\title{
The Ignitability of Flame Retarded Plastics
}

\author{
D. D. DRYSDALE and H. E. THOMSON
}

Unit of Fire Safety Engineering

University of Edinburgh

\begin{abstract}
Measurements of the firepoint temperature and the critical mass flux of some thermoplastics and their flame retarded modifications have been made. The results may be used to confirm or identify the mode of action of the retardant and provide the opportunity to investigate the effectiveness of the retardant treatment under a range of heat fluxes. They reveal clearly the differences between retardants which act in the gas phase and those which act as inert fillers.
\end{abstract}

Keywords: Tgnitability; ignition of solids; flame retardants.

\section{Nomenclature:}

$\begin{array}{ll}\mathrm{B}_{\mathrm{cr}} & \text { Critical value of Spalding's B-number } \\ \mathrm{c} & \text { Specific heat }(\mathrm{kJ} / \mathrm{g}) \\ \mathrm{h} & \text { Convective heat transfer coefficient } \\ & \left(\mathrm{kW} / \mathrm{m}^{2} \mathrm{~K}\right) \\ \dot{m}_{c r}^{\prime \prime} & \text { Critical mass flux at the firepoint } \\ & \left(\mathrm{g} / \mathrm{m}^{2} \mathrm{~s}\right)\end{array}$

$\begin{array}{ll}\text { Greek } & \\ \Delta \mathrm{H}_{\mathrm{c}} & \text { Heat of combustion }(\mathrm{kJ} / \mathrm{g}) . \\ \phi & \begin{array}{l}\text { Maximum fraction of } \Delta \mathrm{H}_{\mathrm{c}} \text { that } \\ \text { flame can lose to surface } \\ \text { without extinguishing. }\end{array}\end{array}$

\section{INTRODUCTION}

The ignition of combustible solids can be described in terms of heat transfer to the surface followed by ignition of the vapour/air mixture in the boundary layer $[1-4]$. The initiation of flaming may be piloted or spontaneous. The latter occurs in the absence of a pilot source (a small flame, or spark) when the surface is exposed to high levels of radiant or convective heating. It is associated inter alia with the later stages of the growth period of a compartment fire when the general level of radiation has increased to that at which the onset of flashover is imminent. On the other hand, the phenomenon of piloted ignition is more relevant to the initiation of fire from a "small" ignition source. Attempts at quantifying the minimum condition for pilot ignition have led to the concepts of a minimum critical heat flux [5] and a critical surface temperature [6], but neither on its own is entirely satisfactory. The problem has been addressed in some detail by Rasbash [2] and Tzeng et al. [3]. Rasbash argued that not only is it necessary to identify a critical surface temperature - the firepoint temperature - but the flowrate of volatiles must also be known as this will determine whether or not stabilisation of a diffusion flame at the surface is possible. 
Thomson has measured the firepoint temperatures for a number of plastics [7] and has been able to show that the ignition condition is associated with a minimum (critical) mass flux of the fuel vapours at the firepoint $[8,9]$. This was first highlighted by Rasbash [2], who argued that a critical value of the Spalding B-number [10] $\left(B_{c r}\right)$ could be calculated from the critical flux $\left(\dot{m}_{c r}^{\prime r}\right)$, as follows:

$\dot{m}_{c r}^{\prime \prime}=\frac{h}{c} \ln \left(1+B_{c r}\right)$

where $h$ is the convective heat transfer coefficient relevant to the nascent diffusion flame losing heat to the surface $\left(\mathrm{kW} / \mathrm{m}^{2} . \mathrm{K}\right)$ and $\mathrm{c}$ is the thermal capacity of air. The critical B-number could in turn be expressed in terms of the ratio $\mathrm{A} / \Delta \Delta \mathrm{H}_{\mathrm{c}}$, where $\mathrm{A}=$ $3000 \mathrm{~kJ} / \mathrm{g}, \Delta \mathrm{H}_{\mathrm{c}}$ is heat of combustion of the fuel vapours $(\mathrm{kJ} / \mathrm{g})$ and $\phi$ is the maximum fraction of the heat of combustion that the diffusion flame can lose to the surface without being extinguished. Rasbash (2) has argued that the maximum possible value of $\phi$ is approximately 0.45 , based on the fraction of the heat of combustion that must be removed from a stoichiometric hydrocarbon/air flame to cause quenching. A somewhat lower value (e.g. 0.3 - 0.4) might be anticipated for the nascent diffusion flame. In principle, $\phi$ is related to the reactivity, or flammability, of the fuel vapours, and can be calculated provided that the critical mass flux at the firepoint can be measured and the heat of combustion of the vapours is known.

Although $\dot{m}_{c r}^{\prime \prime}$ can be measured with some precision [9], the concept is difficult to generalise, due to the uncertainty in the value of $h$, which appears to be apparatus (or "scenario") dependent. Drysdale and Thomson [9] obtained evidence which suggests that the value was very sensitive to the size of the sample and the air flow pattern in its vicinity. Until methods are developed by which reliable values of $h$ can be derived, this particular application of the firepoint concept is unlikely to become generally accepted.

However, the techniques developed to measure these firepoint parameters $\left(\mathrm{T}_{\mathrm{ig}}\right.$ and $\dot{m}_{c r}^{\prime \prime}$ ) can be applied to gather data which are of relevance to the interpretation of the mechanisms of fire retardancy. A limited amount of data have been presented on three common thermoplastics and their fire retarded modifications [8]. In this paper these data, which refer to "gas-phase active" retardants, are compared with results obtained with retardants which are classified as "inert fillers", viz. calcium carbonate $\left(\mathrm{CaCO}_{3}\right.$, or "CC") and alumina trihydrate $\left(\mathrm{Al}_{2} \mathrm{O}_{3} \cdot 3 \mathrm{H}_{2} \mathrm{O}\right.$, or "ATH"). "Solid-phase active" retardants which alter the mode of decomposition of the solid (such as borates and phosphates applied to wood) are not considered here.

\section{EXPERIMENTAL}

The measurement of firepoint temperature and the critical flux at the firepoint were made using the apparatus described in detail elsewhere [7 - 9]. Common thermoplastics and their flame retarded modifications were obtained from commercial sources (Table 1). These were tested as received: not only was it not possible to ascertain the exact nature of the retardant present, but there was no opportunity to 
examine the effect of varying the concentration of the retardant in the polymer.

However, it was possible to prepare samples of polyester containing different amounts of inert filler. Four different loadings $(10 \%, 25 \%, 40 \%$ and $50 \%)$ of each of two fillers ( $\mathrm{CC}$ and $\mathrm{ATH}$ ) were used. The required amount of filler was stirred into the polyester resin (Strand Ltd) and thoroughly mixed, incorporating as little air as possible. The mixture was allowed to stand for ca 10 minutes to allow any air bubbles to rise to the surface. A peroxide initiator ( $1 \%$ by weight of the polyester resin) was then stirred in to initiate the curing process. The mixture was poured into moulds which produced a sufficient number of samples of the size required for the experiments $(65 \mathrm{~mm}$ square and $6 \mathrm{~mm}$ thick). The moulds were placed on a heat sink to prevent distortion due to the heat generated in the curing process. Curing was complete within 24 hours.

\section{TABLE 1. Commercial thermoplastics.}

\begin{tabular}{|lcl|}
\hline \multicolumn{1}{|c}{ Material } & Identifier & \multicolumn{1}{c|}{ Source } \\
\hline Polymethylmethacrylate (PMMA) & PX & Imperial Chemical Industries (ICI) \\
Fire retarded PMMA & PXFR & Imperial Chemical Industries (ICI) \\
Polypropylene & PP & Courtaulds Acetate plc \\
Fire retarded polypropylene & PPFR & Courtaulds Acetate plc \\
Polystyrene & PS & BASF \\
Fire retarded polystyrene & PSFR & BASF \\
\hline
\end{tabular}

For the firepoint measurements, fine thermocouples (Chromel/Alumel, $0.05 \mathrm{~mm}$ diam.) were attached to the centre of the exposed surface of the sampies using methods described elsewhere [7]. With the cast polyester samples, thermocouple junctions were placed on the surface at the centre of each sample shortly after the mix had been poured into the mould. They were held in position by surface tension and after curing were found to be held firmly in place. Thermocouples were not attached to the samples when the purpose of the experiment was to determine the critical mass flux at the firepoint.

Each sample was wrapped in Aluminium foil and placed in a holder which allowed exposure of a circular area of sample $60 \mathrm{~mm}$ in diameter. The foil was carefully peeled away from this area to uncover the upper surface of the sample. A backing board of Kaowool was used to hold the sample rigidly in position within the holder.

Measurements of firepoint temperature and the critical flux at the firepoint were made at a range of heat fluxes up to $40 \mathrm{~kW} / \mathrm{m}^{2}$.

\section{RESULTS}

The data are presented in Tables $2-7$. Each value represents the average of six successful determinations: the reproducibility was good, with standard deviations seldom exceeding $5 \%$ (see references [7] and [8]). The unfilled polyester was found to have a firepoint temperature similar to that of polymethylmethacrylate (PX) ( $c a$ $310^{\circ} \mathrm{C}$ ). The commercially available fire retarded modifications of PX, PP and PS had firepoint temperatures $60-70^{\circ}$ higher than the unmodified materials (Table 2). The 
TABLE 2. Efrect of fire retardants on firepoint temperature (commercial thermoplastics).

\begin{tabular}{|l|c|c|c|c|c|c|}
\hline Heat flux & $\begin{array}{c}\mathbf{1 4} \\
\mathbf{k W} / \mathbf{m}^{\mathbf{2}}\end{array}$ & $\begin{array}{c}\mathbf{1 7} \\
\mathbf{k W} / \mathbf{m}^{2}\end{array}$ & $\begin{array}{c}\mathbf{2 0} \\
\mathbf{k W} / \mathbf{m}^{2}\end{array}$ & $\begin{array}{c}\mathbf{2 4} \\
\mathbf{k W} / \mathbf{m}^{2}\end{array}$ & $\begin{array}{c}\mathbf{3 0} \\
\mathbf{k W} / \mathbf{m}^{2}\end{array}$ & $\begin{array}{c}\mathbf{3 7} \\
\mathbf{k W} / \mathbf{m}^{\mathbf{2}}\end{array}$ \\
\hline Material & & & & & & \\
\hline PX & $288^{*}$ & 312 & 306 & 307 & 306 & 312 \\
\hline PXFR & NI & NI & 368 & 372 & 376 & 377 \\
\hline PP & 317 & 320 & 314 & 330 & 325 & 332 \\
\hline PPFR & NI & NI & NI & NI & 392 & 397 \\
\hline PS & 360 & 362 & 367 & 369 & 365 & 370 \\
\hline PSFR & NI & NI & NI & 430 & 441 & 445 \\
\hline
\end{tabular}

* Units: ${ }^{\circ} \mathrm{C} ; \mathrm{NI}=$ non-ignition.

TABLE 3. Effect of the inert fillers Calcium Carbonate (CC) and Alumina Trihydrate (ATH) on the firepoint temperature of cast polyester.

\begin{tabular}{|c|c|c|c|c|c|c|c|c|c|}
\hline & Filler & $\overline{C C}$ & ATH & $\overline{\mathrm{CC}}$ & ATH & $\mathrm{CC}$ & ATH & $\mathrm{CC}$ & ATH \\
\hline Loading & $0 \%$ & $10 \%$ & $10 \%$ & $25 \%$ & $25 \%$ & $40 \%$ & $40 \%$ & $50 \%$ & $50 \%$ \\
\hline Heat flux & & & & & & & & & \\
\hline $15 \mathrm{~kW} / \mathrm{m}^{2}$ & $310^{*}$ & 312 & 318 & 307 & 324 & 309 & $\mathrm{NI}$ & 314 & עل \\
\hline $26 \mathrm{~kW} / \mathrm{m}^{2}$ & 308 & 312 & 320 & 315 & 324 & 312 & 330 & 307 & 331 \\
\hline $37 \mathrm{~kW} / \mathrm{m}^{2}$ & 310 & 314 & 312 & 308 & 326 & 314 & 331 & 307 & 335 \\
\hline
\end{tabular}

* Units: ${ }^{\circ} \mathrm{C} ; \mathrm{NI}=$ non-ignition.

TABLE 4. Effect of fire retardants on the critical mass flux at the firepoint (commercial thermoplastics).

\begin{tabular}{|l|c|c|c|c|}
\hline Heat Flux & $13 \mathrm{~kW} / \mathrm{m}^{2}$ & $19 \mathrm{~kW} / \mathbf{m}^{2}$ & $25 \mathrm{~kW} / \mathbf{m}^{2}$ & $33 \mathbf{~ k W} / \mathrm{m}^{2}$ \\
\hline Material & & & & \\
\hline PX & $1.90^{*}$ & 1.96 & $1.87)$ & 2.04 \\
\hline PXFR & NI & 4.48 & 4.32 & 5.19 \\
\hline PP & 1.03 & 1.12 & 1.10 & 1.20 \\
\hline PPFR & NI & NI & 2.34 & 3.58 \\
\hline PS & 0.93 & 1.01 & 1.07 & 0.91 \\
\hline PSFR & NI & NI & 4.85 & 5.98 \\
\hline
\end{tabular}

* Units: $g / \mathrm{m}^{2} . \mathrm{s} ; \mathrm{NI}=$ non-ignition. 
TABLE 5. Effect of inert fillers on the critical mass flux (cast polyester).

\begin{tabular}{|c|c|c|c|c|c|c|c|c|c|}
\cline { 2 - 10 } \multicolumn{2}{c|}{} & CC & ATH & CC & ATH & CC & ATH & CC & ATH \\
\hline Heat flux & & & & & & & & & \\
\hline $15 \mathrm{~kW} / \mathrm{m}^{2}$ & $1.97^{*}$ & 2.11 & 2.31 & 2.04 & 2.92 & 1.86 & NI & 2.04 & NI \\
\hline $26 \mathrm{~kW} / \mathrm{m}^{2}$ & 1.83 & 1.97 & 2.71 & 2.10 & 3.05 & 2.07 & 3.20 & 1.88 & 3.39 \\
\hline $37 \mathrm{~kW} / \mathrm{m}^{2}$ & 2.11 & 2.07 & 2.66 & 20.4 & 3.20 & 1.83 & 3.38 & 1.99 & 3.51 \\
\hline
\end{tabular}

* Units: $g / \mathrm{m}^{2} . \mathrm{s} ; \mathrm{NI}=$ non-ignition.

TABLE 6. Effect of fire retardants on time to ignition (commercial thermoplastics).

\begin{tabular}{|l|c|c|c|c|}
\hline Heat Flux & $13 \mathbf{k W} / \mathbf{m}^{2}$ & $19 \mathbf{k W} / \mathbf{m}^{2}$ & $25 \mathbf{k W} / \mathbf{m}^{2}$ & $33 \mathbf{~ k W} / \mathbf{m}^{2}$ \\
\hline Material & & & & \\
\hline PX & $287 \mathrm{~s}$ & $127 \mathrm{~s}$ & $58 \mathrm{~s}$ & $30 \mathrm{~s}$ \\
\hline PXFR & NI & $352 \mathrm{~s}$ & $194 \mathrm{~s}$ & $89 \mathrm{~s}$ \\
\hline PP & $442 \mathrm{~s}$ & $172 \mathrm{~s}$ & $91 \mathrm{~s}$ & $57 \mathrm{~s}$ \\
\hline PPFR & NI & NI & $285 \mathrm{~s}$ & $90 \mathrm{~s}$ \\
\hline PS & $610 \mathrm{~s}$ & $209 \mathrm{~s}$ & $120 \mathrm{~s}$ & $74 \mathrm{~s}$ \\
\hline PSFR & NI & NI & $291 \mathrm{~s}$ & $124 \mathrm{~s}$ \\
\hline
\end{tabular}

$\mathrm{NI}=$ non-ignition.

TABLE 7. Effect of inert fillers on time to ignition (cast polyester).

\begin{tabular}{|c|c|c|c|c|c|c|c|c|c|}
\cline { 2 - 10 } \multicolumn{2}{c|}{} & CC & ATH & CC & ATH & CC & ATH & CC & ATH \\
\hline Loading & $0 \%$ & $10 \%$ & $10 \%$ & $25 \%$ & $25 \%$ & $40 \%$ & $40 \%$ & $50 \%$ & $50 \%$ \\
\hline $15 \mathrm{~kW} / \mathrm{m}^{2}$ & $480 *$ & 491 & 521 & 530 & 603 & 562 & NI & 599 & $\mathrm{NI}$ \\
\hline $26 \mathrm{~kW} / \mathrm{m}^{2}$ & 240 & 245 & 253 & 264 & 292 & 284 & 332 & 298 & 350 \\
\hline $37 \mathrm{~kW} / \mathrm{m}^{2}$ & 61 & 65 & 69 & 75 & 80 & 80 & 96 & 92 & 112 \\
\hline
\end{tabular}

* Units: $s ; \mathrm{NI}=$ non-ignition. 
effect of inert filler on the firepoint of the polyester was very much less: indeed, $50 \%$ $\mathrm{CC}$ produced no change in $\mathrm{T}_{\mathrm{ig}}$, while $50 \% \mathrm{ATH}$ increased $\mathrm{T}_{\mathrm{ig}}$ by only $30-35^{\circ}$ (Table 3). Table 4 and 5 indicate similar trends for the values of the critical mass flux at the firepoint.

All the FR treatments increased the time to ignition under a given heat flux. The change was found to be much less for the inert fillers than for the gas-phase active species (Tables 6 and 7 ).

\section{DISCUSSION}

Earlier work showed that the firepoint temperatures of the oxygenated polymers PMMA and POM lie in the region of $300-310^{\circ} \mathrm{C}$, while those of the hydrocarbon polymers PE, PP and PS lie somewhat higher: data for PMMA, PP and PS are given in Table 2 for reference purposes. The fire retarded modifications of these polymers prove to be more resistant to ignition, in that they cannot be ignited at the lower heat fluxes, and exhibit significantly delayed ignitions at the higher. Their firepoint temperatures are also greater, but it is significant that these increase as the imposed heat flux is increased. "Gas-phase active" fire retardants are progressively lost from the surface layers of the polymer as it is heated and the concentration of the gaseous inhibitors in the fuel vapours will diminish with time of heating [11]. Their effect on the flammability (i.e. reactivity) of the vapours will be at a maximum during the early stages of the heating period. At high heat fluxes, capable of producing high surface temperatures very rapidly, ignition is achieved when the effect of the retardant is high. The data shown in Tables 2 and 4 are consistent with this hypothesis. Not only is a higher "firepoint temperature" recorded, but the critical flowrate is also increased. However, it should be noted that it is not possible from these results to distinguish between the mass flux of the fuel vapours and the loss of the fire retardant species from the fuel surface.

The firepoint temperature of the polyester filled with calcium carbonate is scarcely different to that of the unfilled polymer, even up to $50 \%$ loading. However, it does increase with alumina trihydrate, although the increase is relatively small: the comparison between the two fillers is shown in Figures 1 and 2 .

In earlier papers, the results of the firepoint measurements have been discussed in terms of Rasbash's firepoint equation. By relating $\dot{m}_{c r}^{\prime \prime}$ (see Equation 1 et seq.) to a critical value of Spalding's B-number, it is possible to identify changes in the reactivity of the fuel vapours, which determine the heat transfer characteristics of the nascent flame at the surface at the firepoint condition. As discussed elsewhere $[8,9]$, this calculation requires accurate knowledge of the heat transfer coefficient describing convective heat losses from the flame to the surface. Rasbash ascribed a value of 10 $\mathrm{W} / \mathrm{m}^{2} . \mathrm{K}$, which has also been used by Tewarson [12]. However, this figure leads to values of $\phi$ greatly in excess of 0.45 . The value of $h=10 \mathrm{~kW} / \mathrm{m}^{2} . \mathrm{K}$ is appropriate as an average convective heat transfer coefficient for an upward-facing surface, but it is not relevant in this case. Careful observation reveals that the diffusion flame first becomes established over the centre of the sample, where the local convective heat transfer coefficient is likely to be significantly less than the average value. Al-Arabi and El-Reidy [13] demonstrated this clearly for heat losses by natural convection from 
an upward-facing flat plate, $450 \mathrm{~mm}$ square: the heat transfer coefficient was not constant over the surface, but decreased from the edge, showing a minimum of $<4$ $\mathrm{kW} / \mathrm{m}^{2} . \mathrm{K} 30 \mathrm{~mm}$ from the edge, and a value of approximately $7 \mathrm{~kW} / \mathrm{m}^{2} . \mathrm{K}$ towards the centre.

\section{Calcium carbonate}

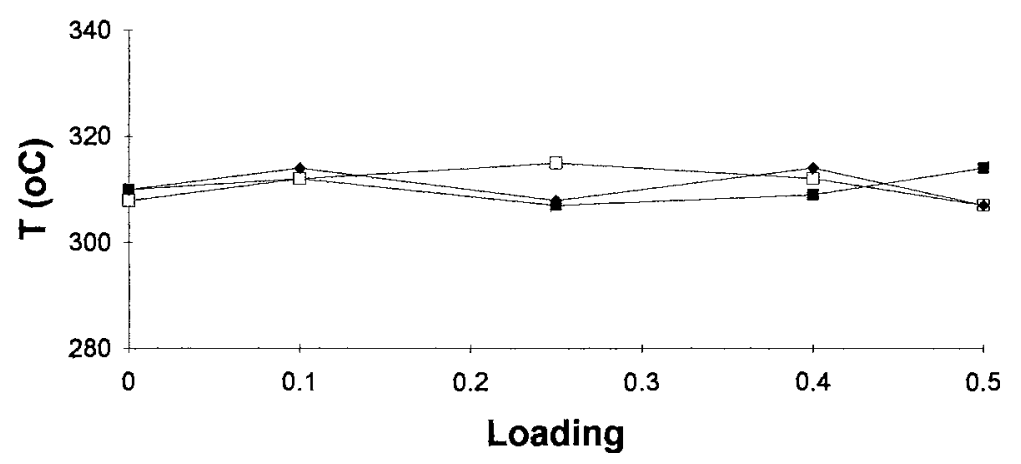

FIGURE 1 Effect of loading on the firepoint temperature of polyester filled with CC. - $15 \mathrm{~kW} / \mathrm{m}^{2} ;$ a $26 \mathrm{~kW} / \mathrm{m}^{2} ; 37 \mathrm{~kW} / \mathrm{m}^{2}$.

\section{Alumina trihydrate}

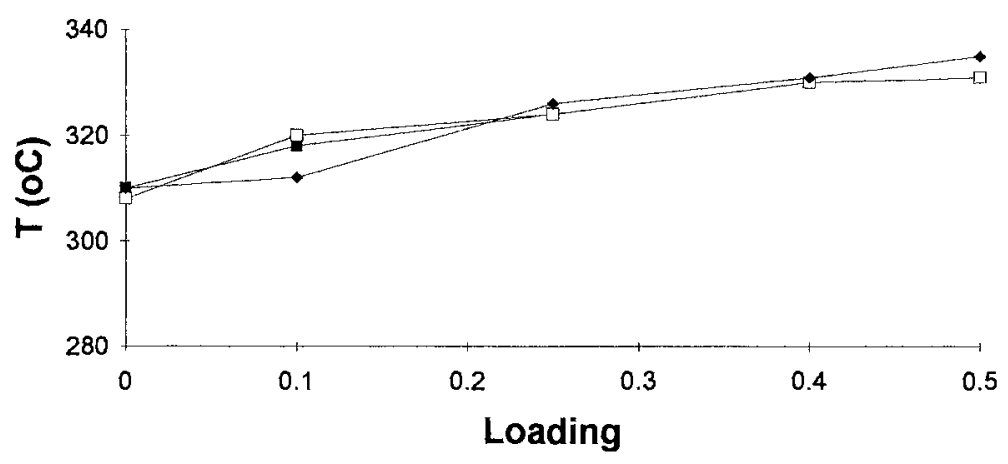

FIGURE 2 Effect of loading on the firepoint temperature of polyester filled with ATH. $15 \mathrm{~kW} / \mathrm{m}^{2} ;$ a $26 \mathrm{~kW} / \mathrm{m}^{2} ; 37 \mathrm{~kW} / \mathrm{m}^{2}$.

These results cannot be compared directly with the heat transfer characteristics of the heated polymer samples, but they suggest that it would be reasonable to assume a lower convective heat transfer coefficient at the centre of the sample. If $5 \mathrm{~W} / \mathrm{m}^{2} . \mathrm{K}$ is used (with $c=1 \mathrm{~J} / \mathrm{g} . \mathrm{K}$ ), then the values of $\phi$ obtained are consistent with the model 
proposed by Rasbash, and may be used to illustrate how $\phi$ varies for non-FR and FR plastics.

Table 8 compares values of $\phi$ for the commercial thermoplastics, with $(\mathrm{h} / \mathrm{c})$ as 5 $\mathrm{g} / \mathrm{m}^{2}$.s. Very large differences are seen for the pairs PXPXFR, PP/PPFR and PS/PSFR in which the FR species act as gas phase inhibitors (Table 8a). If $\phi$ is taken as a measure of the reactivity of the fuel vapours (a low value indicates that less heat can be lost to the surface without the flame self-extinguishing), then it could be used to examine the effectiveness of different fire retardant formulations over a range of heat fluxes.

TABLE 8a. Values of $\phi$ for the commercial thermoplastics.

\begin{tabular}{|ccccccc|}
\hline $\begin{array}{c}\text { Heat Flux } \\
\left(\mathbf{k W} / \mathbf{m}^{\mathbf{2}}\right)\end{array}$ & PX & PXFR & PP & PPFR & PS & PSFR \\
\hline 13 & 0.26 & $\mathrm{NI}$ & 0.30 & $\mathrm{NI}$ & 0.37 & $\mathrm{NI}$ \\
19 & 0.25 & 0.08 & 0.28 & $\mathrm{NI}$ & 0.33 & $\mathrm{NI}$ \\
25 & 0.26 & 0.09 & 0.28 & 0.12 & 0.31 & 0.05 \\
33 & 0.24 & 0.07 & 0.26 & 0.07 & 0.38 & 0.03 \\
\hline
\end{tabular}

TABLE 8b. Values of $\phi$ for the cast polyester.

\begin{tabular}{|cccc|}
\hline $\begin{array}{c}\text { Heat Flux } \\
\left(\mathbf{k W} / \mathbf{m}^{\mathbf{2}}\right)\end{array}$ & PEs & $\begin{array}{c}\text { PEsCC } \\
(\mathbf{4 0 \% )}\end{array}$ & $\begin{array}{c}\text { PEsATH } \\
(\mathbf{4 0} \%)\end{array}$ \\
\hline 15 & 0.25 & 0.27 & $\mathrm{NI}$ \\
26 & 0.27 & 0.23 & 0.13 \\
37 & 0.23 & 0.27 & 0.12 \\
\hline
\end{tabular}

By contrast, $\phi$ is unchanged for the polyester (PEs) when calcium carbonate (CC) is used as an inert filler (Table $8 \mathrm{~b}$ ), even up to $50 \%$ loading. It would appear that the fire retardant action of this particular additive rests on the increased density/thermal inertia of the filled polymer at the higher loadings. Table 9 shows that for $\mathrm{CC}$, the time to ignition at each heat flux is approximately proportional to the density.

The same simple relationship is not observed for ATH, the results indicating that there is an additional FR mechanism involved with this additive. This is not unexpected, as it is well known that ATH decomposes to release its water of crystallisation at temperatures in excess of $200^{\circ} \mathrm{C}$. Not only is this an endothermic process, but the water vapour effectively dilutes the fuel vapours: this can be viewed as a simple "thermal loading" of the vapour, or - more correctly in the context of the firepoint equation - a decrease in the heat of combustion $(\mathrm{kJ} / \mathrm{g})$ of vapour released. The net effect is that a higher rate of evolution of vapours is required (see Table 5), which is reflected as a reduction in $\phi$ if the heat of combustion of the fuel vapours in assumed to remain the same. 
TABLE 9. Polyester plus additive: relationship between $t_{i g}$ and density.

Polyester + Calcium Carbonate

\begin{tabular}{|c|c|c|c|c|c|c|c|}
\hline & \multicolumn{2}{|c|}{$15 \mathrm{~kW} / \mathrm{m}^{2}$} & \multicolumn{2}{|c|}{$26 \mathrm{~kW} / \mathrm{m}^{2}$} & \multicolumn{2}{|c|}{$27 \mathrm{~kW} / \mathrm{m}^{2}$} \\
\hline $\begin{array}{c}\text { Loading } \\
(\%)\end{array}$ & $\begin{array}{c}\text { Density } \\
\left(\mathrm{g} / \mathrm{m}^{3}\right)\end{array}$ & $t_{i g}(s)$ & $\begin{array}{c}\mathbf{t}_{\mathbf{i} \rho} / \rho \\
\left(\mathrm{s} \cdot \mathrm{m}^{3} / \mathrm{g}\right)\end{array}$ & $t_{i p}(s)$ & $\begin{array}{c}t_{\text {ip }} / \rho \\
\left(\mathrm{s} . \mathrm{m}^{3 / g}\right)\end{array}$ & $t_{i \rho}(s)$ & $\begin{array}{c}\mathbf{t}_{\mathrm{i} \rho} / \rho \\
\left(\mathrm{s} . \mathrm{m}^{3} / \mathrm{g}\right)\end{array}$ \\
\hline 0 & 1.3 & 480 & 369 & 240 & 185 & 61 & 47 \\
\hline 10 & 1.37 & 491 & 358 & 245 & 179 & 65 & 47 \\
\hline 25 & 1.49 & 530 & 355 & 264 & 177 & 75 & 50 \\
\hline 40 & 1.64 & 562 & 343 & 284 & 173 & 80 & 49 \\
\hline 50 & 1.75 & 599 & 342 & 298 & 170 & 92 & 53 \\
\hline
\end{tabular}

Polyester + Alumina Trihydrate

\begin{tabular}{|c|c|c|c|c|c|c|c|}
\hline & \multicolumn{2}{|c|}{$15 \mathrm{~kW} / \mathrm{m}^{2}$} & \multicolumn{2}{|c|}{$26 \mathrm{~kW} / \mathrm{m}^{2}$} & \multicolumn{2}{|c|}{$27 \mathrm{~kW} / \mathrm{m}^{2}$} \\
\hline $\begin{array}{c}\text { Loading } \\
(\%)\end{array}$ & $\begin{array}{c}\text { Density } \\
\left(\mathrm{g} / \mathrm{m}^{3}\right)\end{array}$ & $t_{i g}(\dot{s})$ & $\begin{array}{c}\mathbf{t}_{\mathbf{i} \rho} / \rho \\
\left(\mathrm{s} . \mathrm{m}^{3} / \mathrm{g}\right)\end{array}$ & $t_{i p}(s)$ & $\begin{array}{c}t_{i p} / \rho \\
\left(s . m^{3} / g\right)\end{array}$ & $t_{i g}(s)$ & $\begin{array}{c}t_{i \rho} / \rho \\
\left(s . m^{3 / g}\right)\end{array}$ \\
\hline 0 & 1.3 & 480 & 369 & 240 & 185 & 61 & 47 \\
\hline 0.1 & 1.36 & 521 & 383 & 253 & 186 & 69 & 51 \\
\hline 0.25 & 1.47 & 603 & 410 & 292 & 199 & 80 & 54 \\
\hline 0.4 & 1.59 & NI & NI & 339 & 213 & 96 & 60 \\
\hline 0.5 & 1.69 & $\mathrm{NI}$ & $\mathrm{NI}$ & 350 & 207 & 112 & 66 \\
\hline
\end{tabular}

\section{CONCLUSIONS}

The data presented in this paper indicate that a surface temperature criterion for piloted ignition seems to be valid for the fire retarded plastics that were tested, although due recognition must be made of the fact that some of the gas phase retardant may be lost from the solid during prolonged heating periods at low heat fluxes. By using the critical mass flux at the firepoint as a criterion for piloted ignition, as proposed by Rasbash, useful data may be gleaned about the mechanisms of fire retardancy. However, more work is required on the detailed heat and mass transfer characteristics associated with an upward facing surface before the firepoint equation can be used more widely.

\section{ACKNOWLEDGEMENTS}

The authors are most grateful to the Home Office for its support of this project. 


\section{REFERENCES}

1. Kanury, A.M., Fire Research Abstracts and Reviews, 14 24 - 52 (1972).

2. Rasbash, D.J., International Symposium on Fire Safety of Combustible Materials, (University of Edinburgh, 1976) pps. 169 - 178

3. Tzeng, L.S., Atreya, A and Wichman I.S. Combustion and Flame $\underline{80} 94-107$ (1990).

4. Delichatsios, M.A., Panagiotou, Th. and Kiley, F. Combustion and Flame, $\underline{84}$ 323 (1991)

5. Rasbash, D.J. and Drysdale, D.D. Fire and Materials 779 - 88 (1983).

6. Thomson, H.E., Drysdale, D.D. and Beyler, C.L., Fire Safety Journal $\underline{13} 185$ 196 (1988).

7. Thomson, H.E. and Drysdale D.D., Fire and Materials 11165 - 178 (1988).

8. Drysdale, D.D. and Thomson, H.E. Second International Symposium on Fire Safety Science, (Hemisphere Publishing Corporation, 1989) pps. 67 - 76.

9. Drysdale, D.D. and Thomson H.E., Fire Safety Journal 14179 - 188 (1989).

10. Spalding, D.B. "Some Fundamentals of Combustion" (Butterworths, London, 1955).

11. Lyons, J.W. "The Chemistry and Uses of Fire Retardants" (John Wiley \& Sons, New York, 1970).

12. Tewarson, A. "Experimental evaluation of flammability parameters of polymeric materials" in M. Lewin, S.M. Atlas and E.M. Pearce (eds.) "Flame Retardant Polymeric Materials Volume 3" (Plenum Press, 1982) pps. 97 153.

13. Al-Arabi, M. and El-Reidy, M.K. Int. J. Heat and Mass Transfer, 191399 (1976). 